\title{
Occupational Stress and Burnout Prevalence Among Agricultural Education Lecturers in Nigerian Universities
}

\author{
Francis M. Onu ${ }^{1}$, Benedicta A. Omeje ${ }^{1}$, Cajethan U. Ugwuoke ${ }^{1}$, Felicia N. Ezebuiro ${ }^{1}$, Lilian U. Ekenta ${ }^{1}$, \\ Regina N. Mgbenka ${ }^{1}$, Clara U. Nwankwo ${ }^{1}$, Frederick C. Onah ${ }^{1}$, Christiana Nwachukwu ${ }^{1}$, Godwin E. Eze ${ }^{1}$, \\ Theresa C. Omeje ${ }^{1}$, Uchenna S. Ekwueme ${ }^{1}$, Evelyn N. Odo ${ }^{1}$, Emeka K. Ogbonna ${ }^{1} \&$ Francisca N. Arokwu ${ }^{1}$ \\ ${ }^{1}$ Department of Agricultural Science Education, University of Nigeria Nsukka, Enugu State, Nigeria \\ Correspondence: Benedicta A. Omeje, Department of Agricultural Science Education, University of Nigeria \\ Nsukka, Enugu State, Nigeria. E-mail: benedicta.omeje@unn.edu.ng
}

Received: October 20, 2019 Accepted: November 19, 2019 Online Published: November 21, 2019

doi:10.5539/gjhs.v11n14p58 URL: https://doi.org/10.5539/gjhs.v11n14p58

\begin{abstract}
Occupational Stress and Burnout has become a serious challenge to Lecturers in recent time due to increased job and family role conflicts and student's population explosion resulting in more workload on the side of the lecturers. This study aimed to investigate occupational stress and burnout prevalence among agricultural education lecturers in Nigerian universities. The study adopted a cross-sectional survey research design and was conducted in Nigerian universities. A self-structured questionnaire was used as an instrument for data collection. Descriptive and inferential statistics were used to analyze the data collected. The results indicated the presence of occupational burnout in the studied sample. The study, therefore, recommended further investigations on the appropriate preventive measures and equally supports some research findings on the importance of developing interventions or therapies to reduce existing problems.
\end{abstract}

Keywords: prevalence, occupational stress, burnout, agricultural education, Nigerian universities

\section{Introduction}

Agricultural education is aimed at training and imparting knowledge and skill to its recipients in the field of agriculture such as crop production, livestock management, soil and water conservation, and marketing among others. Egbule (2004) posited that agricultural education is the type of education that is concerned with training learners in the improved agricultural production processes and the techniques for the teaching of agriculture. Osinem (2007) stated that agricultural education has trained the youths in the skills necessary to assume leadership positions, lifelong knowledge and soft skills that employers seek as well as the creation of future entrepreneurs. These are achieved with the help of lecturers in universities.

A lecturer of agricultural education is an individual who had undergone a teacher preparatory programme in the university and charged with the responsibility of imparting to the students the knowledge, skills and attitudes in agriculture.Ekenechukwu and Osaat (2017) stated that lecturers are the greatest assets as well as major stakeholders in the university-industry. The authors affirmed that other than these, lecturers are also exposed to varieties of other duties some of which are complex and sometimes conflicting with their primary roles as teachers and academic staff. Some of these duties include; carrying out research, preparing and delivering regular lectures to students; Conducting tutorial sessions, seminars and laboratory classes (where necessary); adapting to the shift to e-learning, combining work and home activities, attending conferences and contributing to the development of research strategies for the School among others.

There is no doubt that these groups of lecturers are occupied with lots of responsibilities which are all good, worth doing but may have some negative effects on the bearer either internally or externally. Some lecturers, in order to meet up with these responsibilities, combine office and home shores while at home. Cascio and Montealegre (2016) emphasized that employees after leaving the workplace can stay connected to their jobs due to technological advancement. The authors further stated that employees can stay connected to their job even after leaving the workplace. Such technology advances could potentially increase work hours and conflicts between work and home life. In certain cases, the work-family conflict has been associated with increased poor workability and job stress among others. Ekenechukwu et al. (2017) stated that stress associated with one's job could be referred to occupational stress. 
Occupational stress is widely known to affect all profession and category of workers. Mohajan (2012) viewed occupational stress as the harmful physical and emotional responses that occur when the demands of the job exceed the capabilities, needs or resources of the worker. In the submission of CWA (2018), occupational stress could be referred to a state of tension which occurs when a person senses a disagreement between the working environment challenges and their possibilities of coping. The author stated that occupational stress has been linked to incapability to work, absenteeism, anxiety, increased rate of accident on and off the job. In the submission of Ogbuanya, Eseadi, Orji, Ohanu, Bakareand Ede (2017), occupational stress can lead to maladjustment in the workplace and equally to occupational health-related problems.

Occupational health-related problems occur at the workplace or because of the nature of one's work. It is a condition that results from too much workload or from exposure in a workplace to a chemical, biological or physical agent to the extent that the normal physiological mechanisms are affected and the health of the worker is impaired (Tyrer, 2018). The author further stated that occupational health-related problems include cuts, broken bones, stains, loss of limbs, repetitive motion disorder, cardiovascular disorder, asthma, depression, gastric ulcer, skeletal or muscular problems, hearing problem, vision, respiratory disorder cancer and high blood pressure among others. The author emphasized that they develop over a long time because of workplace conditions and when they develop, they affect the worker's workability. Tengland (2011) posited that having workability means having the occupational competence and the health required in an occupational for managing the work tasks, assuming that the tasks are reasonable and that the work environment is acceptable. With this, it is obvious that occupation health-related problems and excess workload lead to inefficiency among workers. Timisoara (2016) in support of this, pointed out that occupation health-related problems result in dissatisfaction and low achievement which equally lead to anxiety, depression and frustrations among others. Ellis (2004) emphasized that when people are depressed emotionally they feel exhausted which is a sign of burnout.

Burnout is an emotional problem which affects workers productivity. In the view of Melinda, Jeane, Lawrence and Robert (2019), burnout is a reaction to chronic job stress and is characterized by three main aspects: exhaustion, cynicism and feelings of decreased professional efficacy. More simply put, if one feels exhausted; start to hate his/her job, and begins to feel less capable of carrying out his work roles, such an individual is showing signs of burnout. In line with the above, Bahar (2017) pointed out that burnout result to work/family conflict, cynicism, poor personal accomplishment, emotional exhaustion, cardiac arrest, mental imbalance, and death among others. The author emphasized that these burnout symptoms are common among workers that are faced with many responsibilities. Agricultural education lecturers are not left out in this problem as they are saddled with lots of responsibilities. As indicated earlier, this affects their productivities, homes, health as well as other work-related behaviours. The need therefore to minimize this ugly trend in the system cannot be overemphasized. When this issue is tackled, it is hoped that Agricultural education lecturers will be effective in attending to their responsibilities.

\subsection{Statement of the Problem}

Lecturers in Nigerian universities are faced with the duties of teaching, research, supervision at different levels and family co-ordination among others. In the same way, lecturers of agricultural education in addition to the above duties are involved in some practical work experience with the students. During these practical works, they engage themselves in strenuous activities such as processing, handling animals and some of its by-products, chemicals, and machines among others which are in most cases hazardous (resulting to chemical, biological, mechanical, sociological and physical hazards among others). Numerous duties mentioned above lead to the excessive workload which in turn result in stress both in the universities and at home. The condition associated with the duties results to occupational stress and occupational health-related problems such as cuts, broken bones, stains, loss of limbs and cardiovascular disorder among others. Today researchers have proven that job-related stress has a negative effect on the individual concerned. Stress has been proven to be a major contributor to some diseases that can impede the individual from performing effectively in their workplaces such as cardiac arrest, vision problem, mental problem, spinal problem and hypertension among others. A lot of illnesses and deaths have been observed happening among university lecturers.

Furthermore, this stress result to problems like job dissatisfaction, maladjustment in the workplaces, deviant behaviours, frustration, irrational thoughts/belief, work/family role conflict, cynicism, poor personal accomplishment and emotional exhaustion among others. Agricultural education lecturers due to their workload are prone to these ugly problems, hence, the need to find out the prevalence of these problems and seek for an available solution. 


\subsection{Purpose of the Study}

The general purpose of the study is to find out the occupational stress and burnout prevalence among agricultural education lecturers in Nigerian universities. Specifically, the study will investigate occupational stress and burnout prevalence among agricultural education lecturers in Nigerian universities.

\section{Methods}

This study adopted a cross-sectional survey research design. The study was conducted in Nigerian Universities. Six universities comprising one university each from the six geopolitical zones of Nigeria was randomly selected for the study. The study has a population of 82 respondents, which consisted of agricultural education lecturers in the sampled universities. The instrument for data collection was a structured general health questionnaire. The questionnaire has three different sections A, B, C, which elicited information on symptoms of work stress, burnout symptoms and frequency of work stress respectively. Descriptive and inferential statistics were used to analyze the collected data.

\section{Results}

Table 1. Demographic Characteristics of Respondents

\begin{tabular}{lllc}
\hline Variables & Categories & N & Percentage \\
\hline \multirow{2}{*}{ Gender } & Male & 35 & 42.7 \\
& Female & 47 & 57.3 \\
\hline \multirow{3}{*}{ Year of Experience } & $1-5$ years & 58 & 70.7 \\
& $6-10$ years & 11 & 13.4 \\
& $11-15$ years & 9 & 11.0 \\
& 16 years and above & 4 & 4.9 \\
\hline \multirow{2}{*}{ Age } & $20-35$ years & 33 & 40.2 \\
& $36-45$ years & 6 & 7.3 \\
Marital Status & $46-60$ years & 43 & 52.4 \\
\hline \multirow{2}{*}{ Academic Qualification } & Married & 64 & 78.0 \\
& Single & 18 & 22.0 \\
\hline
\end{tabular}

As shown in Table 1, male agricultural education lecturers that participated in the study were 35(42.7\%) while the females were $47(57.3 \%)$. Greater number of the lecturers that participated was less experienced with dominant category of $>1-5$ years numbering $58(70.7 \%)$ a little number of moderately experienced lecturers of $6-10$ years numbering $11(30.4 \%)$ and highly experienced lecturers of $11-15$ years and 16 years and above numbering $9(11.0 \%)$ and $4(4.9 \%)$ respectively. The Table also indicated that up to $43(52.4 \%)$ who participated in the study have reached 46-60 years, 33(40.2\%) are between 20-35 years while the other 6(7.3\%) lecturers fall within the age bracket 36-45 years. It also indicated that 64 respondents (78.0) are married while 18(22.0\%) are single. In terms of academic qualification, most of these lecturers, up to 41(50.0) have their Master degree, Doctor of Philosophy are 26(31.7) whereas the remaining 15(18.3) have Bachelors degree. 


\section{Research Question 1}

What is the prevalence of occupational stress among male and female Agricultural Education lecturers in Nigerian Universities? Table 2a was used to answer research question 1

Table 2a. Frequency and percentages of the responses of respondent on the prevalence of occupational stress among male and female agricultural education lecturers

\begin{tabular}{lllllll}
\hline \multirow{2}{*}{ Gender } & \multicolumn{2}{c}{ Responses } & Somewhat & Often & Frequency & Almost always \\
\cline { 2 - 5 } & Never & Occasionally & & 16 & 7 & 3 \\
\hline Male & 2 & 1 & 6 & $45.7 \%$ & $20.0 \%$ & $8.6 \%$ \\
\% within sex & $5.7 \%$ & $2.9 \%$ & $17.1 \%$ & 23 & 10 & 0 \\
Female & 1 & 1 & 12 & $48.9 \%$ & $21.3 \%$ & $0.0 \%$ \\
Percentage & $2.1 \%$ & $2.1 \%$ & $25.5 \%$ & & & \\
\hline
\end{tabular}

Table 2b. Chi-Square Test

\begin{tabular}{lccc}
\hline & p-value & Df & $\begin{array}{c}\text { Asymptotic Significance } \\
(\mathbf{2}-\mathbf{5} \text { sided) }\end{array}$ \\
\hline Pearson chi-square & & $5.480^{\circ}$ & .360 \\
Likelihood Ratio & 6.570 & 5 & .255 \\
Linear-of-linear Association & 2.00 & 1 & .590 \\
No of valid cases & 82 & & \\
\hline
\end{tabular}

This Table 2a indicates that occupational stress is prevalent among male and female lecturers. Two male lecturers (5.7\%) indicated never had occupational stress, $1(2.9 \%)$ occasionally, $6(17.1 \%)$ responded somewhat, $16(45.7 \%)$ often, $7(20.0 \%)$ frequently and $3(8.6 \%)$ indicated almost always. For female lecturers, $1(2.1 \%)$ indicated never, $1(2.1 \%)$ occasionally, $12(25.5 \%)$ somewhat, $23(48.9 \%)$ often, $10(21.3 \%)$ frequently and nobody $(0.0 \%)$ indicated almost always. The chi-square test also reveals that significant difference does not exist in the percentage responses of male and female lecturers in the prevalence of occupational stress among agricultural education lecturers in Nigerian universities.

\section{Research Question 2}

What is the prevalence of occupational stress among newly employed and experienced Agricultural Education lecturers in Nigerian Universities. Table $3 \mathrm{a}$ was used to answer research question 2

Table 3a. Frequency and percentage of the responses of respondent on the occupational stress prevalence among newly employed and experienced agricultural education lecturers in Nigerian universities

\begin{tabular}{|c|c|c|c|c|c|c|}
\hline \multirow{2}{*}{ Year of Experience } & \multicolumn{2}{|c|}{ Responses } & \multirow{2}{*}{ Somewhat } & \multirow{2}{*}{ Often } & \multirow{2}{*}{ Frequency } & \multirow{2}{*}{ Almost always } \\
\hline & Never & Occasionally & & & & \\
\hline \multirow{2}{*}{$1-5$ years Percentage } & 2 & 2 & 15 & 26 & 11 & 2 \\
\hline & $3.4 \%$ & $3.4 \%$ & $25.9 \%$ & $48.8 \%$ & $19.0 \%$ & $3.4 \%$ \\
\hline \multirow{2}{*}{ 6- 10 years Percentage } & 0 & 0 & 2 & 6 & 2 & 1 \\
\hline & $0.0 \%$ & $0.0 \%$ & $18.2 \%$ & $54.5 \%$ & $18.2 \%$ & $9.1 \%$ \\
\hline \multirow{2}{*}{$11-15$ years } & 1 & 0 & 1 & 4 & 3 & 0 \\
\hline & $11.1 \%$ & $0.0 \%$ & $11.1 \%$ & $44.4 \%$ & $33.3 \%$ & $0.0 \%$ \\
\hline \multirow{2}{*}{16 years and above } & 0 & 0 & 0 & 3 & 1 & 0 \\
\hline & $0.0 \%$ & $0.0 \%$ & $0.0 \%$ & $75.0 \%$ & $25.0 \%$ & $0.0 \%$ \\
\hline
\end{tabular}


Table 3b. Chi-square Tests

\begin{tabular}{lccc}
\hline & Value & Df & $\begin{array}{c}\text { Asymptotic Significance } \\
\mathbf{( 2 - 5} \text { sided })\end{array}$ \\
\hline Pearson chi-square & & 15 & .963 \\
Likelihood Ratio & $6.811^{\curvearrowright}$ & 15 & .888 \\
Linear-of-linear Association & 8.802 & 1 & .494 \\
No of valid cases & .467 & & \\
\hline
\end{tabular}

Table 3 shows that agricultural education lecturers no matter the years of experienced are entangled with occupational stress. As indicated in their response categories, for those that have less than 1-5 years experience 2 lecturers (3.4\%) never had occupational stress, another 2 (3.4\%) occasionally, 15 of them (25.9\%) somewhat, 26 $(48.8 \%)$ had it often, $11(19.0 \%)$ indicated frequently and the last $2(3.4 \%)$ had it almost always. For those with teaching experience of 6-10 years, no lecturer never or occasionally had occupational stress, $2(18.2 \%)$ indicated somewhat, $6(54.5 \%)$ often, $2(18.2 \%)$ frequently and $1(9.1 \%)$ almost always. For those with working experience of $11-15$ years, 1 person $(11.1 \%)$ never had occupational stress, nobody $(0.0 \%)$ occasionally or almost always had occupational stress, $1(11.1 \%)$ indicated somewhat, $4(44.4 \%)$ often and $3(33.3 \%)$ frequently. Then for the highly experienced lecturers of 16 years and above, nobody indicated to have never, occasionally, somewhat or almost always had occupational stress thereby recording $0.0 \%, 3(75.0 \%)$ indicated to have often and only $1(25.0 \%)$ was frequently.

$\mathbf{H O}_{2}$ : The chi-square, based on years of experience revealed, that significant difference does not exist in the percentage score of agricultural education lecturers in Nigerian universities on the prevalence of occupational stress.

\section{Research Question 3}

What is the Prevalence of Occupational stress among aged and younger Agricultural Education lecturers in Nigerian Universities? Table 4 A was used to answer this research question.

Table 4a.Frequency and percentages responses of the respondents on the prevalence of occupational stress among different age level (20-35, 36-45 and 46-60 years) of Agricultural Lecturers in Nigeria universities

\begin{tabular}{lllllll}
\hline \multirow{2}{*}{ Age } & \multicolumn{2}{l}{ Responses } & Somewhat & Often & Frequency & Almost always \\
\cline { 2 - 6 } & Never & Occasionally & & 12 & 9 & 1 \\
\hline 20-35 years Percentage & 2 & 2 & $21.2 \%$ & $36.4 \%$ & $27.3 \%$ & $3.0 \%$ \\
\hline 36-45 years & $6.1 \%$ & $6.1 \%$ & 0 & 5 & 1 & 0 \\
Percentage & 0 & 0 & $0.0 \%$ & $83.3 \%$ & $16.7 \%$ & $0.0 \%$ \\
\hline 46-60 years & $0.0 \%$ & $0.0 \%$ & 11 & 22 & 7 & 2 \\
Percentage & 1 & 0 & $25.6 \%$ & $51.2 \%$ & $16.3 \%$ & $4.7 \%$ \\
\hline
\end{tabular}

Table 4b. Chi-square Tests

\begin{tabular}{lllc}
\hline & Value & Df & $\begin{array}{c}\text { Asymptotic Significance } \\
\mathbf{( 2 - 5} \text { sided })\end{array}$ \\
\hline Pearson chi-square & & 10 & .475 \\
Likelihood Ratio & 9.614 & 10 & .304 \\
Linear-of-linear Association & 11.717 & 1 & .646 \\
No of valid cases & 211 & & \\
\hline
\end{tabular}


Table 4a shows that agricultural education lecturers at different age level experience occupational stress. Among the lecturers that are within the age level of $20-35,2(6.1 \%)$ indicated never had occupational stress, $2(6.1 \%)$ occasionally, 17(21.2\%) somewhat, 12(36.4\%) often, 9(27.3\%) frequently and 1(3.0) is almost always. For those lecturers within 36-45 years, none $(0.0 \%)$ indicated never, occasionally and somewhat, $5(83.3 \%)$ often, $1(16.7 \%)$ frequently and nobody again indicated almost always thereby recording $(0.0 \%)$. Then for those within 46-60years of age, only $1(2.3 \%)$ indicated never had occupational stress, nobody $(0,0 \%)$ indicated occasionally, 11(25.6\%) somewhat, 22(51.2\%) often, 7(16.3\%) frequently and 2(4.7\%) indicated almost always. The chi-square in Table $4 \mathrm{~b}$ shows that significant difference does not exist in the percentage score of the respondents on the prevalence of occupational stress among Agricultural Education lecturers that are within the age level of 20-35, 36-45 and 46-60 years of age.

\section{Research Question 4}

What is the occupational stress prevalence among married and single agricultural education lecturers in Nigerian Universities? Table 5a was used to answer this research question.

Table 5a. Frequency and percentages of responses of the respondents on the prevalence of occupational stress among married and single agricultural education lecturers in Nigerian Universities

\begin{tabular}{|c|c|c|c|c|c|c|}
\hline \multirow{2}{*}{ Marital Status } & \multicolumn{2}{|c|}{ Responses } & \multirow{2}{*}{ Somewhat } & \multirow{2}{*}{ Often } & \multirow{2}{*}{ Frequently } & \multirow{2}{*}{ Almost always } \\
\hline & Never & Occasionally & & & & \\
\hline Married & 3 & 2 & 12 & 31 & 14 & 2 \\
\hline Percentage & $4.7 \%$ & $3.1 \%$ & $18.8 \%$ & $48.4 \%$ & $21.9 \%$ & $3.1 \%$ \\
\hline Single & 0 & 0 & 6 & 8 & 3 & 1 \\
\hline Percentage & $0.0 \%$ & $0.0 \%$ & $33.3 \%$ & $44.4 \%$ & $16.7 \%$ & $5.6 \%$ \\
\hline
\end{tabular}

Table 5b. Chi-square Tests

\begin{tabular}{lccc}
\hline & Value & Df & $\begin{array}{c}\text { Asymptotic Significance } \\
(\mathbf{2}-\mathbf{5} \text { sided })\end{array}$ \\
\hline Pearson chi-square & 13.225 & 5 & .665 \\
Likelihood Ratio & 4.154 & 5 & .527 \\
Linear-of-linear Association & .041 & 1 & .840 \\
No of valid cases & 82 & & \\
\hline
\end{tabular}

Table 5a shows that agricultural education lecturers both married and single are entangled with occupational stress. For the married agricultural education lecturers, 3 persons (4.7\%) responded never had occupational stress, 2(3.1\%) occasionally, $12(18.8 \%)$ somewhat, $31(48.4 \%)$ often, $14(21.9 \%)$ frequently and $2(3.1 \%)$ indicated almost always whereas for the lecturers that are single none of them $(0.0 \%)$ indicated never or occasionally had occupational stress, $6(33.3 \%)$ somewhat, $8(44.4 \%)$ often $3(16.7 \%)$ frequently and $1(5.6 \%)$ indicated almost always. The chi-square in Table $5 \mathrm{~b}$ indicated that a significant difference does not exist in the percentage score of married and single Agricultural education lecturers on the prevalence of occupational stress.

\section{Research Question 5}

What is the prevalence of occupational stress among Agricultural Education lecturers with different academic qualifications (Bachelor's degrees, master degree and Doctor of philosophy) in Nigerian universities. Table 6a was used to answer research question 5. 
Table 6a. Frequency and percentage of the responses the respondent on the prevalence of occupational stress among agricultural education lecturers with different academic qualification (Bachelor's degrees, Masters Degree and Doctor of Philosophy) in Nigerian Universities

\begin{tabular}{lcccccc}
\hline \multirow{2}{*}{ Academic Qualification } & \multicolumn{2}{l}{ Responses } & Somewhat & Often & Frequency & $\begin{array}{c}\text { Almost } \\
\text { always }\end{array}$ \\
\cline { 2 - 6 } Never & Occasionally & & 4 & 4 & 6 & 0 \\
\hline Bachelors & 0 & 1 & $26.7 \%$ & $26.7 \%$ & $40.0 \%$ & $0.0 \%$ \\
Percentage & $0.0 \%$ & $6.7 \%$ & 6 & 23 & 7 & 2 \\
Masters degree & 2 & 1 & $14.6 \%$ & $56.1 \%$ & $17.1 \%$ & $4.9 \%$ \\
Percentage & $4.9 \%$ & $2.4 \%$ & 8 & 12 & 4 & 1 \\
Doctor of philosophy & 1 & 0 & $30.8 \%$ & $46.2 \%$ & $15.4 \%$ & $3.8 \%$ \\
Percentage & $3.8 \%$ & $0.0 \%$ & & & & \\
\hline
\end{tabular}

Table 6b. Chi-square Tests

\begin{tabular}{lccc}
\hline & Value & Df & $\begin{array}{l}\text { Asymptotic Significance } \\
(\mathbf{2}-\mathbf{5} \text { sided })\end{array}$ \\
\hline Pearson chi-square & $10.568^{\circ}$ & 10 & .392 \\
Likelihood Ratio & 11.633 & 10 & .310 \\
Linear-of-linear Association & .389 & 1 & .533 \\
No of valid cases & 82 & & \\
\hline
\end{tabular}

Table 6a shows that there prevalence of occupation stress among agricultural education lecturers irrespective of their academic qualifications of a bachelor degree, master degree and doctor of philosophy. In the response categories of those with a bachelor degree, no lecturer $(0.0 \%)$ never had occupational stress, $1(6.7 \%)$ occasionally, 4(26.7\%) somewhat and often respectively, $6(40.0 \%)$ indicated frequently and nobody responded almost always. For those with a master degree, $2(4.9 \%)$ indicated never had occupational stress, $1(2.4 \%)$ occasionally, $6(14.6 \%)$ somewhat, $23(56.1 \%)$ often, $7(17.1 \%)$ frequently and the remaining $2(4.9 \%)$ indicated almost always. Then for those with doctor of philosophy degree, 1 person $(3.8 \%)$ indicated never had occupational stress, nobody $(0.0 \%)$ occasionally, $8(30.8 \%)$ somewhat, $12(46.2 \%)$ often, $4(15.4 \%)$ said frequently and the last person $(3.8 \%)$ indicated almost always. The chi-square in Table $6 \mathrm{~b}$ revealed that a significant difference does not exist in the percentage responses of agricultural education lecturers with different qualifications on the prevalence of occupational stress.

\section{Research Question 6}

What is the Prevalence of Burnout among male and female Agricultural Education lecturers in Nigerian Universities. Table $7 \mathrm{a}$ was used to answer research question 6

Table 7a. Frequency and percentage of the responses of respondents on the prevalence of burnout symptoms among male and female agricultural education lecturers in Nigerian universities

\begin{tabular}{|c|c|c|c|c|c|c|}
\hline \multirow{2}{*}{ Gender } & \multicolumn{2}{|l|}{ Response } & \multirow{2}{*}{ Somewhat } & \multirow{2}{*}{ Often } & \multirow{2}{*}{ Frequency } & \multirow{2}{*}{ Almost always } \\
\hline & Never & Occasionally & & & & \\
\hline Male & 2 & 1 & 6 & 16 & 4 & 6 \\
\hline Percentage & $5.7 \%$ & $2.9 \%$ & $17.1 \%$ & $45.7 \%$ & $11.4 \%$ & 17.1 \\
\hline Female & 1 & 2 & 11 & 23 & 8 & 2 \\
\hline Percentage & 2.1 & $4.3 \%$ & $23.4 \%$ & $48.9 \%$ & $17.0 \%$ & $4.3 \%$ \\
\hline
\end{tabular}


Table 7b.Chi-square Tests

\begin{tabular}{lccc}
\hline & Value & Df & $\begin{array}{c}\text { Asymptotic Significance } \\
(\mathbf{2}-\mathbf{5} \text { sided })\end{array}$ \\
\hline Pearson chi-square & 5.080 & 5 & .406 \\
Likelihood Ratio & 5.125 & 5 & .401 \\
Linear-of-linear Association & .556 & 1 & .456 \\
No of valid cases & 82 & & \\
\hline
\end{tabular}

Table $7 \mathrm{a}$ - present the prevalence of burnout symptoms among male and female agricultural education lecturers in Nigeria Universities. The Table shows that agricultural education lecturers irrespective of sex are having burnout concerning their job. In response categories of male lecturers, $2(5.7 \%)$ indicated never had occupational stress, $1(2.9 \%)$ occasionally, $6(17.1 \%)$ somewhat, $16(45.7 \%)$ responded often, $4(11.4 \%)$ frequently and the remaining $6(17.1 \%)$ almost always. For the female, $1(2.1 \%)$ indicated never had occupational stress, $2(4.3 \%)$ occasionally, $11(23.3 \%)$ somewhat, $23(48.9 \%)$ often, $8(17.0 \%)$ frequently and the last $2(4.3 \%)$ indicated almost always. The chi-square in Table $7 \mathrm{~b}$ revealed that a significant difference does not exist in the percentage score of both male and female lecturers on the prevalence of burnout symptoms among agricultural education lecturers in Nigerian universities.

\section{Research Question 7}

What is the Prevalence of Burnout among newly employed and experienced Agricultural Education lecturers in Nigerian Universities? Table 8a was used to answer research question 7.

Table 8a. Frequency and Percentage of the Responses of the Respondents on the Prevalence of Burnout Symptom among Agricultural Education Lecturers in Nigerian Universities based on their year of experience

\begin{tabular}{|c|c|c|c|c|c|c|}
\hline \multirow{2}{*}{ Year of Experience } & \multicolumn{2}{|c|}{ Response } & \multirow{2}{*}{ Somewhat } & \multirow{2}{*}{ Often } & \multirow{2}{*}{ Frequency } & \multirow{2}{*}{ Almost always } \\
\hline & Never & Occasionally & & & & \\
\hline $1-5$ years & 2 & 3 & 13 & 27 & 7 & 6 \\
\hline Percentage & $3.4 \%$ & $5.2 \%$ & $22.4 \%$ & $46.6 \%$ & $12.1 \%$ & $10.3 \%$ \\
\hline $6-10$ years & 0 & 0 & 3 & 5 & 2 & 1 \\
\hline Percentage & $0.0 \%$ & $0.0 \%$ & $27.3 \%$ & $45.5 \%$ & $18.2 \%$ & $9.1 \%$ \\
\hline \multirow{2}{*}{$11-15$ years } & 1 & 0 & 1 & 4 & 2 & 1 \\
\hline & $11.1 \%$ & $0.0 \%$ & $11.1 \%$ & $44.4 \%$ & $22.2 \%$ & $11.1 \%$ \\
\hline \multirow{2}{*}{16 years and above } & 0 & 0 & 0 & 3 & 1 & 0 \\
\hline & $0.0 \%$ & $0.0 \%$ & $0.0 \%$ & $75.0 \%$ & $25.0 \%$ & $0.0 \%$ \\
\hline
\end{tabular}

Table 8b. Chi-square Tests

\begin{tabular}{|c|c|c|c|}
\hline & Value & Df & $\begin{array}{l}\text { Asymptotic Significance } \\
\qquad(2-5 \text { sided })\end{array}$ \\
\hline Pearson chi-square & $7.657^{\circ}$ & 15 & .937 \\
\hline Likelihood Ratio & 9.254 & 15 & .864 \\
\hline Linear-of-linear Association & .782 & 1 & .377 \\
\hline No of valid cases & 82 & & \\
\hline
\end{tabular}

Table 8a present the prevalence of burnout symptoms among newly employed and experienced agricultural education lecturers in Nigerian Universities. The Table shows that both newly employed and experienced lecturers are having burnout symptoms in respect to their job activities. For those within 1-5 years of experience $2(3.4 \%)$ 
indicated never experienced burnout symptoms, 3(5.2\%) occasionally, 13(22.4\%) somewhat, 27(46.6\%) often, $7(12.1 \%)$ frequently and 6(10.3\%) indicated almost always. For those with 6-10 years experience, nobody indicated never or occasionally had burnout symptoms, $3(27.3 \%)$ somewhat, $5(45.5 \%)$ often, $2(18.2 \%)$ frequently and $1(9.1 \%)$ indicated almost always. Lecturers with 11-15 years experience, 1(11.1\%) indicated never experienced burnout symptom, nobody $(0.0 \%)$ responded occasionally, $1(11.1 \%)$ each responded somewhat and almost always respectively, 4(44.4\%) often and 2(22.2\%) frequently. Lastly, for those 16 years and above experience, nobody $(0.0 \%)$ indicated never, occasionally and somewhat experience burnout symptoms, $3(75.0 \%)$ responded often, $1(25.0 \%)$ frequently and nobody $(0.0 \%)$ responded almost always.

The -square in Table $8 \mathrm{~b}$ shows that there is no significant difference in the percentage score of agricultural education lecturers with different years of experience on the prevalence of burnout symptoms.

\section{Research Question 8}

What is the Prevalence of Burnout among old and young Agricultural Education lecturers in Nigerian Universities? Table $9 \mathrm{a}$ was used to answer research question 8 .

Table 9a. Frequency and percentage of the responses of the respondents on the prevalence of burnout symptoms among old and young agricultural education lecturers in Nigerian Universities

\begin{tabular}{|c|c|c|c|c|c|c|}
\hline \multirow{2}{*}{ Age } & \multicolumn{2}{|c|}{ Responses } & \multirow{2}{*}{ Somewhat } & \multirow{2}{*}{ Often } & \multirow{2}{*}{ Frequency } & \multirow{2}{*}{ Almost always } \\
\hline & Never & Occasionally & & & & \\
\hline $20-36$ years & 2 & 3 & 6 & 12 & 7 & 3 \\
\hline Percentage & $6.1 \%$ & $9.1 \%$ & $18.2 \%$ & $36.4 \%$ & $21.2 \%$ & $9.1 \%$ \\
\hline $36-45$ years & 0 & 0 & 0 & 5 & 1 & 0 \\
\hline Percentage & $0.0 \%$ & $0.0 \%$ & $0.0 \%$ & $83.3 \%$ & $16.7 \%$ & $0.0 \%$ \\
\hline $46-60$ years & 1 & 0 & 11 & 22 & 4 & 5 \\
\hline Percentage & $2.3 \%$ & $0.0 \%$ & $25.6 \%$ & $51.2 \%$ & $9.3 \%$ & $11.6 \%$ \\
\hline
\end{tabular}

Table 9b. Chi-square Tests

\begin{tabular}{lccc}
\hline & Value & Df & $\begin{array}{c}\text { Asymptotic Significance } \\
\mathbf{( 2 - 5} \text { sided) }\end{array}$ \\
\hline Pearson chi-square & $12.42^{\circ}$ & 10 & .258 \\
Likelihood Ratio & 15.165 & 10 & .126 \\
Linear-of-linear Association & .327 & 1 & .568 \\
No of valid cases & 82 & & \\
\hline
\end{tabular}

Table 9apresents the prevalence of burnout symptoms among agricultural education lecturers in Nigerian Universities based on age. The Table shows that agricultural education lecturers at different age level show burnout symptoms in respect to their job performance. For the young lecturers within the age of 20-35 years of age, 2(6.1\%) indicated never experienced burnout, 3(9.1\%) occasionally, 6(18.2\%) somewhat, $12(36.4 \%)$ experienced it so often, $7(21.2 \%)$ frequently and $3(9.1 \%)$ almost always. For those within 36-45 years of age, no lecturer $(0.0 \%)$ indicated never, occasionally and somewhat experienced burnout symptoms, $5(83.3 \%)$ often, $1(16.7 \%)$ frequently and nobody $(0.0 \%)$ responded almost always. Then for the older lecturers within the age of 46-60 years old, $1(2.3 \%)$ indicated never had burnout, nobody $(0.0 \%)$ responded occasionally, 11(25.6\%) somewhat, 22(51.2\%) often, $4(9.3 \%)$ frequently and 5(11.6\%) indicated almost always.

The chi-square in 9B revealed that a significant difference does not exist in the percentage score of agricultural education lecturers at different age level on the prevalence of burnout symptoms. 


\section{Research Question 9}

What is the Prevalence of Burnout among married and single Agricultural Education lecturers in Nigerian Universities? Table 10a was used to answer research question 9.

Table 10a. Frequency and percentages of the responses of the respondents in the prevalence of burnout symptoms among married and single agricultural education lecturers in Nigerian Universities

\begin{tabular}{lcccccc}
\hline \multirow{2}{*}{ Marital Status } & \multicolumn{2}{c}{ Responses } & Somewhat & Often & Frequency & Almost always \\
\cline { 2 - 5 } & Never & Occasionally & & 32 & 9 & 6 \\
Married & 3 & 3 & 11 & $50.0 \%$ & $14.1 \%$ & $9.4 \%$ \\
Percentage & $4.7 \%$ & $4.7 \%$ & 6 & 7 & 3 & 2 \\
Single & 0 & 0 & $33.3 \%$ & $38.9 \%$ & $16.7 \%$ & $11.1 \%$ \\
Percentage & $0.0 \%$ & $0.0 \%$ & & & & \\
\hline
\end{tabular}

Table 10b. Chi-square Tests

\begin{tabular}{lccc}
\hline & Value & Df & $\begin{array}{c}\text { Asymptotic Significance } \\
(\mathbf{2}-\mathbf{5} \text { sided) }\end{array}$ \\
\hline Pearson chi-square & 3.927 & 5 & .560 \\
Likelihood Ratio & 5.036 & 5 & .412 \\
Linear-of-linear Association & 204 & 1 & .652 \\
No of valid cases & 82 & & \\
\hline
\end{tabular}

Table 10a presents the prevalence of burnout symptoms among married and single agricultural education lecturers in Nigerian Universities. The Table shows that both married and single agricultural education lecturers experience burnout symptoms in their job activities. For the married lecturers, 3 persons $(4.7 \%)$ indicated never experienced burnout in their work endeavour, another 3(4.7\%) occasionally, 11(17.2\%) somewhat, 32(50.0\%) often, $9(14.1 \%)$ said frequently and the last $6(9.4 \%)$ responded somewhat. Then for the single lecturers, none of them indicated never or occasionally experienced burnout symptoms recording $(0.0 \%), 6(33.3 \%)$ responded somewhat, $7(38.9 \%)$ often, $3(16.7 \%)$ frequently and the last $2(11.1 \%)$ indicated almost always.

The chi-square in Table 10b indicates that a significant difference does not exist in the percentage score of both married and single agricultural education lecturers on the prevalence of burnout symptoms.

\section{Research Question 10a}

What is the Prevalence of Burnoutamongagricultural education lecturers with Bachelors degree, Masters and Doctor of Philosophy. Table 11a was used to answer research question 10.

Table 11a. Frequency and percentages of the Response of the Respondents on the Prevalence of Burnout among Agricultural Education Lecturers according to qualifications

\begin{tabular}{|c|c|c|c|c|c|c|}
\hline \multirow{2}{*}{ Variable: Academic Qualification } & \multicolumn{2}{|l|}{ Responses } & \multirow{2}{*}{ Somewhat } & \multirow{2}{*}{ Often } & \multirow{2}{*}{ Frequency } & \multirow{2}{*}{ Almost always } \\
\hline & Never & Occasionally & & & & \\
\hline Bachelor degree & 0 & 2 & 3 & 4 & 5 & 1 \\
\hline Percentage & $0.0 \%$ & $13.3 \%$ & $20.0 \%$ & $26.7 \%$ & $33.3 \%$ & $6.7 \%$ \\
\hline Masters & 2 & 1 & 8 & 21 & 5 & 4 \\
\hline Percentage & $4.9 \%$ & $2.4 \%$ & $19.5 \%$ & $51.2 \%$ & $12.2 \%$ & $9.8 \%$ \\
\hline \multirow{2}{*}{ Doctor of PhilosophyPercentage } & 1 & 0 & 6 & 14 & 2 & 3 \\
\hline & $3.8 \%$ & $0.0 \%$ & $23.1 \%$ & $53.8 \%$ & $7.7 \%$ & $11.5 \%$ \\
\hline
\end{tabular}


Table 11b. Chi-square Tests

\begin{tabular}{lccc}
\hline & Value & Df & $\begin{array}{c}\text { Asymptotic Significance } \\
(\mathbf{2}-\mathbf{5} \text { sided })\end{array}$ \\
\hline Pearson chi-square & $12.322^{\circ}$ & 10 & .264 \\
Likelihood Ratio & 11.754 & 10 & .302 \\
Linear-of-linear Association & 004 & 1 & .947 \\
No of valid cases & 82 & & \\
\hline
\end{tabular}

Table 11a presents the prevalence of burnout symptoms among agricultural education lecturers with different academic qualifications. The Table shows that agricultural education lecturers despite their academic level exhibit burnout symptoms in respect to their job as a lecturer. As indicated in the Table, agricultural education lecturers that have bachelor degree never experience burnout in their work activities thereby recording $0.0 \%, 2(13.3 \%)$ responded occasionally, $3(20.0 \%)$ somewhat, $4(26.7 \%)$ often, $5(33.3 \%)$ frequently and $1(6.7 \%)$ almost always. For those with master degree, 2 people (4.9\%) indicated never experience burnout symptoms, 1(2.4\%) responded occasionally, $8(19.5 \%)$ somewhat, $21(51.2 \%)$ experience burnout symptoms often, $5(12.2 \%)$ frequently and the last $4(9.8 \%)$ responded almost always. For those with doctor of philosophy, 1 person $(3.8 \%)$ indicated never experience burnout symptoms, nobody responded occasionally and thereby recorded $(0.0 \%), 6(23.1 \%)$ somewhat, 14(53.8\%) responded often, $2(7.7 \%)$ frequently and 3(11.5\%) indicated almost always.

The chi-square in Table 11b shows that significant difference does not exist in the percentage score of agricultural education lecturers with a bachelor degree, master degree and doctor of philosophy on the prevalence of burnout symptoms.

Table 12. Mean and ANOVA analysis of the prevalence of occupational stress among agricultural education lecturers

\begin{tabular}{|c|c|c|c|c|c|c|}
\hline Variables & Categories & $\mathbf{N}$ & $\mathbf{M} \pm \mathbf{S D}$ & Df & $\mathbf{F}$ & P-value \\
\hline \multirow{2}{*}{ Gender } & Male & 35 & $3.29 \pm 0.94$ & \multirow{2}{*}{1,80} & \multirow{2}{*}{0.86} & \multirow{2}{*}{0.36} \\
\hline & Female & 47 & $3.11 \pm 0.81$ & & & \\
\hline \multirow{4}{*}{ Years of Experience } & $1-5$ years & 58 & $3.13 \pm 0.88$ & \multirow{4}{*}{3,78} & \multirow{4}{*}{0.39} & \multirow{4}{*}{0.76} \\
\hline & $6-10$ years & 11 & $3.35 \pm 1.71$ & & & \\
\hline & $11-15$ years & 9 & $3.21 \pm 1.14$ & & & \\
\hline & 16 years and above & 4 & $3.50 \pm 0.41$ & & & \\
\hline \multirow{3}{*}{ Age } & $20-35$ years & 33 & $3.08 \pm 1.01$ & \multirow{3}{*}{2,79} & \multirow{3}{*}{0.55} & \multirow{3}{*}{0.58} \\
\hline & $36-45$ years & 6 & $3.45 \pm 0.39$ & & & \\
\hline & $46-60$ years & 43 & $3.22 \pm 0.79$ & & & \\
\hline \multirow{3}{*}{ Academic Qualification } & Bachelor degree & 15 & $3.13 \pm 0.91$ & \multirow{3}{*}{2,79} & \multirow{3}{*}{0.23} & \multirow{3}{*}{0.80} \\
\hline & Master degree & 41 & $3.25 \pm 0.88$ & & & \\
\hline & Doctor of philosophy & 26 & $3.11 \pm 0.84$ & & & \\
\hline \multirow{2}{*}{ Marital Status } & Married & 64 & $3.17 \pm 0.90$ & \multirow{2}{*}{1,80} & \multirow{2}{*}{0.11} & \multirow{2}{*}{0.74} \\
\hline & Single & 18 & $3.24 \pm 0.74$ & & & \\
\hline
\end{tabular}

Table 12 presents the results of the mean prevalence of occupational stress among agricultural education lecturers. The Table shows that agricultural education lecturers in different categories are having occupational stress. As indicated in their mean score, male and female agricultural education lecturers had a mean score of 3.29 and 3.11 respectively. For years of experience, those lecturers within 1-5 years had a mean score of 3.13, 6-10 years (3.35), 11-15 years (3.21) and those within 16 years and above had 3.50. In terms of age, the lecturers that are within 20-35 years of age had a mean score of 3.08; 36-45 years (3.45), then $46-60$ years of age had 3.22. For academic 
qualifications, those with a bachelor degree had a mean score of 3.13, master degree (3.25) and then doctor of philosophy degree had 3.11. For marital status, lecturers that are married had a mean score of 3.17 while the single ones had a mean score of 3.24. Also, the closeness of the standard deviation score of the responses in all the categories indicates that less variability exists among the responses. The Table also indicates from the ANOVA that significant difference does not exist in the mean score of agricultural education lecturers on the prevalence of occupational stress based on gender, years of experience, age, academic qualifications and marital status.

Table 13. Mean and ANOVA Analysis of the prevalence of Burnout Symptoms among Agricultural Education Lecturers

\begin{tabular}{|c|c|c|c|c|c|c|}
\hline Variables & Categories & $\mathbf{N}$ & $\mathbf{M} \pm \mathbf{S D}$ & Df & $\mathbf{F}$ & P-value \\
\hline \multirow{2}{*}{ Gender } & Male & 35 & $3.37 \pm 0.97$ & \multirow{2}{*}{1,80} & \multirow{2}{*}{0.19} & \multirow{2}{*}{0.67} \\
\hline & Female & 47 & $3.29 \pm 0.80$ & & & \\
\hline \multirow{4}{*}{ Years of Experience } & $1-5$ years & 58 & $3.26 \pm 0.90$ & \multirow{4}{*}{3,78} & \multirow{4}{*}{0.61} & \multirow{4}{*}{0.61} \\
\hline & $6-10$ years & 11 & $3.62 \pm 0.56$ & & & \\
\hline & $11-15$ years & 9 & $3.29 \pm 1.14$ & & & \\
\hline & 16 years and above & 4 & $3.52 \pm 0.40$ & & & \\
\hline \multirow{3}{*}{ Age } & $20-35$ years & 33 & $3.20 \pm 1.04$ & \multirow{3}{*}{2,79} & \multirow{3}{*}{0.72} & \multirow{3}{*}{0.49} \\
\hline & $36-45$ years & 6 & $3.60 \pm 0.42$ & & & \\
\hline & $46-60$ years & 43 & $3.38 \pm 0.78$ & & & \\
\hline \multirow{2}{*}{ Marital Status } & Married & 64 & $3.30 \pm 0.91$ & \multirow{2}{*}{1,80} & \multirow{2}{*}{0.09} & \multirow{2}{*}{0.77} \\
\hline & Single & 18 & $3.38 \pm 0.74$ & & & \\
\hline \multirow{3}{*}{ Academic Qualification } & Bachelor degree & 15 & $3.31 \pm 0.93$ & \multirow{3}{*}{2,79} & \multirow{3}{*}{0.04} & \multirow{3}{*}{0.96} \\
\hline & Master degree & 41 & $3.35 \pm 0.90$ & & & \\
\hline & Doctor of philosophy & 26 & $3.29 \pm 0.83$ & & & \\
\hline
\end{tabular}

Table 13 presents the mean and ANOVA Analysis of the prevalence of burnout symptoms among agricultural education lecturers. The Table shows that agricultural education lecturers at different categories specify in the Table exhibit burnout symptoms. Male and female agricultural education lecturers had a mean score of 3.37 and 3.29 respectively. In terms of years of experience, those within 1-5 years experience had a mean score of 3.26 , 6-10 years (3.62), 11-15 years (3.29) and 16 years and above had 3.52. Agricultural education lecturers that are within 20-35 years of age had a mean score of $3.20 ; 36-45$ years (3.60) and those within 46-60 years old had 3.38. For academic qualification, those with bachelor degree had a mean score of 3.31, master degree had 3.35 and those with a doctor of philosophy degree had 3.29. In the area of marital status, married lecturers had a mean score of 3.30 while the single counterpart had 3.38. Also, the closeness of the standard deviation scores of the responses in all the categories indicates less variability that exists among the responses. The ANOVA analysis also shows that significant difference does not exist in the mean score of agricultural education lecturers on the prevalence of burnout based on gender, years of experience, age, academic qualifications and marital status.

\section{Discussion}

The study showed that the percentage of female agricultural education lecturers that participated are higher than males with $57.3 \%$ and $42.7 \%$ respectively. The result also indicated that up to $52.4 \%$ of the participants have reached $46-60$ years, $40.2 \%$ are between $20-35$ years while the other $7.3 \%$ fell within the age of $36-45$ years. The result also indicated that $78 \%$ of the respondents are married while the remaining $22 \%$ are single. Finally, the result here revealed that up to $50 \%$ of the participants have a master degree, $31.7 \%$ have a doctor of philosophy degree and the remaining $18.3 \%$ have a bachelor degree.

The finding of the study in Table 2a showed that occupational stress is prevalent among male and female agricultural education lecturers. It also revealed that female lecturers experienced occupational stress than their male counterparts. This was in line with the finding of Rohit, Yatan and Chanda (2011), who reported that men and women react differently with stress both biologically and psychologically. Rothmann and Barkhuizen (2008) in support of this stated that female (academic) workers often report higher levels of exhaustion than their male 
colleagues.

Table 3a showed that less experienced lecturers that have $<1-5$ years experience have more occupational stress than the experienced lecturers. This was in line with the finding of Hanson (2001) who reported that an average older worker due to experience, exhibits expertness and manage stress nous condition.

The finding in Table 4a indicated that agricultural education lecturers at all age level experience occupational stress. However, those lecturers within the age level 36-45 years experience occupation stress than other age levels. Osipow and Daty (2000) in support of this reported that middle-aged workers with their experience and high status in the work organization, experience more stress emanating from their responsibility for people and workload but less stress based on conditions of their physical environment.

The finding in Table 5a showed that agricultural education lecturers that are not married experienced occupational stress more than their married counterparts. Marriage in most cases normally goes with age. As the case may be, these married lecturers are 90\% older than single lecturers. In line with this, Mcheand (2016) reported that older workers have more self-regulation skills when compared to younger workers. The author explained that this helps them to manage strenuous condition both of home and in the workplace.

The finding in Table 6a indicated that lecturers experience occupational stress despite their academic qualification. The finding also revealed that those with bachelor degree experience occupational stress more than others with higher qualification. This is in line with the findings of Rothmann and Barkhiuzen (2008) who reported that working at low carder lead to strain. The authors emphasized that this strain leads to occupational stress and maladjustment in workplaces.

The finding in Table 7a showed that both male and female lecturers have burnout symptoms. The Table also revealed that females have more burnout symptoms than male counterparts. This is in line with the finding of Templeton et al. (2019) who reported that woman physician experience burnout symptoms like emotional exhaustion than male mainly due to work-life integration among others.

The finding in Table 8a showed that agricultural education lecturers despite years of experience still suffer burnout symptoms. The Table revealed that lecturers with $<1-5$ years of experience have burnout more than their counterparts. This is in line with the report of Coetzee, Maree and Smit (2019) who observed from the study they conducted with novice and experienced teachers that the novice who is less experience suffer more burnout symptoms than the experienced teachers.

The finding of Table 9a showed that agricultural education lecturers react to burnout at a different level. This is shown by the percentage responses. The Table revealed that the prevalence of burnout is more from 36 years and above. This finding supports the earlier finding of Marchand, Blanc, and Beauregard (2018) who found that age was linearly related to cynicism and reduced professional efficacy. The author further explained that burnout level decrease with increasing age in men, but increases in women from 25 years and above. Hui-chusan (2018) in line with the above, reported that older workers show increase level of burnout due to some factors such as physical strength limitations, health concerns and gap related to using new technology in the workplace.

From the analysis in Table 10a, it was found that both married and single agricultural education lecturers suffer burnout in relation to their work. This is shown in their responses. The Table revealed that single lecturers suffer burnout more than the married lecturers. Ali (2014) in line with the above finding reported that single educational stakeholders exhibit emotional exhaustion and depersonalization more than married ones while married stakeholders report reduce personal achievement than single ones. The author further explained that a healthy family seems as support to the partners that are experiencing burnout at work.

The findings in Table 11a showed that agricultural education lecturers despite their academic qualification suffer burnout symptoms. The Table revealed that workers with bachelor degree exhibit burnout symptoms more than those with higher qualifications. Rothmann and Barkhuizen (2008) in line with the above finding reported that workers with a doctoral degree are less likely to report burnout than those with a master degree or bachelor degree. The author further emphasized that most stress-related problems seem to be more common among workers with low status and poor education. The author posited that rank as a potential status resource is an active variable in predicting workplace burnout.

The finding in Table 12a showed that agricultural education lecturers in different categories are entangled with occupational stress. This was observed in terms of gender, age, years of experience, marital status, and academic qualifications. At each category, it was observed that the mean was above 2.49. This in line with the finding of Ekenechuchukwu\&Osaat (2017), who reported that workers with excess workload are prone to occupational stress no matter your level and category. 
The finding in Table 13 showed that burnout symptoms cut across every category. As indicated in the Table, burnout is prevalent by gender, years of experience, different age levels, marital status and academic qualifications. Rothmann and Barkhinzen (2008) reported that burnout affects all professions and workers at different categories but how significant it is, depends on the type of work, personal characteristics and work environment among others.

\section{Conclusion and Recommendations}

In conclusion, our study revealed significant occupational stress and burnout prevalence among agricultural education lecturers in Nigerian universities. Among the contributing factors to this issue include too much workload and family - work role interferences. The study, therefore, recommends further investigations in other tertiary institutions other than the university with regard to the risk factors of burnout among agricultural education lecturers. The study also emphasizes the importance of developing interventions or therapies to help prevent these symptoms as this could go a long way in helping agricultural education lecturers to improve on their job performance and productivity.

\section{Competing Interests Statement}

The authors declare that there are no competing or potential conflicts of interest.

\section{References}

Ali, K. (2014). Marital status differences in burnout among educational stakeholders: A meta-analysis. International Journal of Human Science, 11(2), 543-555. https://doi.org/10.14687/ijhs.v11i2.2922

Bahar, G. (2017). Depression: Causes, Symptoms and Treatment. Retrieved from livescience.com

Cascio, W. F., \& Montealegre, R. (2016). How Technology Is Changing Work and Organizations. Annual Review of Organizational Psychology and Organizational Behavior, 3(1), 349-375

Communication Workers of America (CWA). (2018). Occupational stress and the workplace.Occupational safety and health department. Retrieved from https://www.CWAunion.org

Egbule, P. E. (2002). Fundamentals and practice of agricultural education.Owerri: TOTAN publisher.

Ekechukwu, R., \& Osaat D. S. (2017). Managing workload of academic staff for job effectiveness in Nigerian Universities: A study of University of Port Harcourt, South-South Geopolitical Zone of Nigeria. Department of Educational Management, Faculty of Education, University of Port Harcourt.

Ellis, A. (2004). Why Rational Emotive Behaviour Therapy is the Most Comprehensive and Effective Form of Behaviour Therapy. Journal of Rational-Emotive \& Cognitive Behaviour Therapy, 22(2), 85-92. https://doi.org/10.1023/B:JORE.0000025439.78389.52

Hansson R. O., Dekoek, P. D., Neece, W. M., \& Paterson, O. W. (1996). Successful aging at work: The older worker and transition to retirement. Journal of Vocational Behavior, 51, 25-29.

Ibrahim, H. E. (2014). The problem and prospect of Agriculture Education in Nigeria. Journal of Resourcefulness and Distinction, 7(1), 1-9.

Marchand, A., Blanc, M. E., \& Beauregard, N. (2018). Do age and gender contribute to workers burnout symptoms? Journal of Occupational Medicine, 68(6), 404-411.https://doi.org/10.1093/occmed/kqy088

Melinda, S., Jeane, S., Lawrence, R., \& Robert, S. (2019). Burnout Prevention and Treatment: Techniques for dealing with overwhelming stress. Retrieved from helpguide.org

Mohajan. (2012). The occupational stress and risk of it among the employees. International Journal of Mainstream Social Science, 2(2), 17-34.

Coetzee, N., Maree, D., \& Smit, B. (2019). The relationship between chronic fatigue syndrome, burnout, job satisfaction, social support and age among academics at a tertiary institution. International Journal of Occupational Medicine and Environmental Health, 32(1), 75-85.

Ogbuanya, T. C., Eseadi, C., Orji, C. T., Ede, M. O., Ohanu, I. B., \& Bakare, J. (2017). Effects of rational emotive occupational health therapy intervention on the perceptions of organizational climate and occupational risk management practices among electronics technology employees in Nigeria. Medicine, 96(18), e6765. https://doi.org/10.1097/MD.0000000000006765

Omorogbe, O., Jelena, Z., \& Fatima, A. (2014).The role of agriculture in the economic development of Nigeria. European Scientific Journal,10(4), 133-147. 
Osinem, E. C. (2007). Faces of agricultural education in Nigeria: Issues and challenges. A seminar paper presented to the department of agricultural education (College of agricultural and science education, University of agriculture, Makurdi).

Osipow, S. H., \& Dorty, R. E. (2000). Occupational stress, strain and coping across the life span. Journal of Vocational Behavior, 27(10), 98-108. https://doi.org/10.1016/0001-8791(85)90055-7

Rohit, V., Yatan, P. B., \& Chanda, S. G. (2011). Gender differences in stress response: Role of developmental and biological determinants. Industrial Psychiatry Journal, 20(1), 1-4. https://doi.org/10.4103/0972-6748.98407

Rothmann, S., \& Barkhuizen, N. L. (2008). Burnout of academic staff in South Africa higher education institutions. South Africa Journal of Higher Education, 1-19. https://doi.org/10.4314/sajhe.v22i2.25796

Templeton, K., Bernstein, C. A., Sukhera, J., Nora, L. M., Newman, C., Burstin, H., ... \& Busis, N. (2019). Gender-based differences in burnout: Issues faced by women physicians. NAM Perspectives. Discussion Paper, National Academy of Medicine, Washington, DC. https://doi.org/10.31478/201905a

Timisoara, R. (2016). EASOM summer school managing and teaching workability. Retrieved from https://www.easom.eu

Tyer, F. H. (2018). Problems of occupational health in Nigeria. Occupational Medicine, 18(2). https://doi.org/10.1093/occmed/18.2.105

\section{Copyrights}

Copyright for this article is retained by the author(s), with first publication rights granted to the journal.

This is an open-access article distributed under the terms and conditions of the Creative Commons Attribution license (http://creativecommons.org/licenses/by/4.0/). 